\title{
Histórias em quadrinhos e suas múltiplas linguagens
}

\author{
Maria Cristina Xavier de Oliveira ${ }^{1}$
}

RESUMO: Esta comunicação objetiva destacar o aspecto semiótico da linguagem dos quadrinhos, sobretudo no que diz respeito a sua relação com os recursos cinematográficos tão presentes neste importante meio de comunicação.

ABSTRACT: This paper aims to emphasize the semiotic features of the comics' language, mainly in regarding to its relationship with the cinematographic resources that appear in this important means of communication.

PALAVRAS-CHAVE: Quadrinhos; linguagem; cinema; comunicação.

KEYWORDS: Comics; language; cinema; communication.

A interação entre diferentes linguagens e recursos é uma das marcas presentes no processo de comunicação humana, sobretudo atualmente. Neste contexto, a história em quadrinhos (HQ) tem se mostrado como importante veículo de integração de múltiplos recursos comunicativos, revelando assim grande potencial expressivo e possibilitando a construção de diversas narrativas.

Antes da expansão dos quadrinhos pelo mundo, a utilização da imagem acompanhada ou não de texto já era praticada por muitos povos ao longo dos tempos. Aliás, se remontarmos à história da civilização humana, encontraremos a linguagem pictórica utilizada para narrar acontecimentos e fenômenos da natureza.

As HQs foram prenunciadas na Europa através de histórias representadas por imagens acompanhadas de textos, como no caso das Histoires en Estampes (1846-47), de Rodolphe Topffer, escritor, artista e professor universitário natural de Genebra. Contudo, é nos Estados Unidos que elas florescem e encontram grande sucesso. Os primeiros quadrinhos americanos apareceram nos jornais e seu principal objetivo era o humorístico.

Em termos de disseminação, as HQs só tiveram ampliado seu consumo através dos Syndicates. Criados a partir da primeira década do século 20 pelos jornais, para contratar e

\footnotetext{
${ }^{1}$ Doutoranda em Estudos Comparados de Literaturas de Língua Portuguesa. FFLCH-USP. Pesquisa: Letras e Desenhos - A construção narrativa revelada através da inter-relação Literatura e Quadrinhos. E-mail: mariacristina.mc@ig.com.br.
} 
vender o trabalho dos desenhistas, os Syndicates se configuraram como grandes distribuidores de quadrinhos nos Estados Unidos e no mundo.

No Brasil, a tradição das HQs está mais ligada ao humor. Um dos primeiros a produzir quadrinhos foi o ítalo-brasileiro Angelo Agostini, caricaturista e ilustrador que lançou em 1869, no jornal Vida Fluminense, As Aventuras de Nhô Quim ou Impressões de uma viagem à Corte, primeira historieta com personagem fixo ${ }^{2}$. Contudo, as obras nacionais de quadrinhos sofreram desde o início a competição da produção estrangeira, sobretudo a americana, que domina grande parte do mercado até hoje.

\section{Múltiplas linguagens}

Contrastes entre luz e sombras, mudanças de perspectiva, conflito de linhas, além de vários outros elementos, podem ser encontrados em diversos meios, seja em uma história em quadrinhos (HQ), filme, desenho animado ou romance, só para citar alguns exemplos. Não desconsiderando que cada meio tenha suas características próprias, fazendo uso de recursos específicos, ainda assim é possível identificar uma relação de proximidade entre estes. Um exemplo disso é o que ocorre com os quadrinhos e o cinema, artes que estabelecem amplo diálogo já que fazem uso, muitas vezes, de elementos semelhantes na elaboração de suas obras.

É interessante observar como os quadrinhos, um suporte de comunicação de massa extremamente visual, no qual as imagens surgem estáticas no papel, conseguem efeitos tão próximos aos do cinema, uma arte que trabalha com imagens e sons em movimento. Fazendo uso de recursos próprios como o desenho, as linhas, as cores, o texto etc., os quadrinhos, um dos primeiros meios de comunicação de massa a se globalizar antes mesmo do cinema, conseguem extrapolar o papel, garantindo assim a elaboração de narrativas extremamente ágeis e com características bastante cinematográficas, em muitos momentos.

\section{Espaço e montagem}

Segundo Scott McCloud em seu livro Desvendando Quadrinhos (M. Books, 2002), as HQs se configuram como imagens pictóricas e outras justapostas em seqüência

\footnotetext{
${ }^{2}$ MOYA, Álvaro. História das histórias em quadrinhos. São Paulo: Brasiliense, 1994.
} 
deliberada. Temos, pois, além das ilustrações, outras "imagens" presentes nos quadrinhos, como a verbal, que assume um caráter pictórico neste meio. A justaposição se dá pela sua característica seqüencial. Mas não se trata apenas de um ajuntamento de linguagens - na verdade, as relações entre estas várias linguagens é que se torna, nos quadrinhos, mais importante do que as próprias linguagens em si.

Vale destacar que, assim como os desenhos animados, as HQs também se constroem em seqüência, mas diferem daqueles pelo seu aspecto espacial, uma vez que nos desenhos animados a animação é seqüencial em tempo (cada quadro é projetado no mesmo espaço, que é a tela), enquanto nos quadrinhos os quadros ocupam espaços diferentes no papel. A utilização do espaço neste meio é, portanto, um importante recurso para sua composição.

Neste contexto, a montagem se torna fator primordial para a utilização do espaço e a conseqüente construção da narrativa. Apesar de estar diretamente relacionada com a elaboração de obras fílmicas, a montagem não se restringe ao cinema. Conforme ressalta Sergei Eisenstein, "o conceito de montagem está presente em toda a cultura humana. O pensamento humano é montagem..." (EISENSTEIN, 2002, p.8). Nos quadrinhos, por sua vez, a montagem não apresenta todos os enquadramentos num fluxo contínuo como acontece em um filme, mas revela em poucos elementos o essencial para que o leitor, através de sua imaginação, complete os quadros colaborando decisivamente para o processo de montagem. Este movimento, aliás, realizado pelo leitor, é o que McCloud (2002) chama de "conclusão", e que permite conectar momentos dissociados e concluir mentalmente uma realidade contínua e unificada.

A transição entre os quadros nas HQs se revela, portanto, fator decisivo para garantir a composição da narrativa. Essa transição pode se dar de várias maneiras, desde uma representação de cada pequena mudança nas cenas ou nos movimentos até longas alterações de tempo, espaço, aspecto, idéias e sentidos. Cada escolha na forma de apresentar o transcorrer dos quadros resultará em efeitos diferentes. 


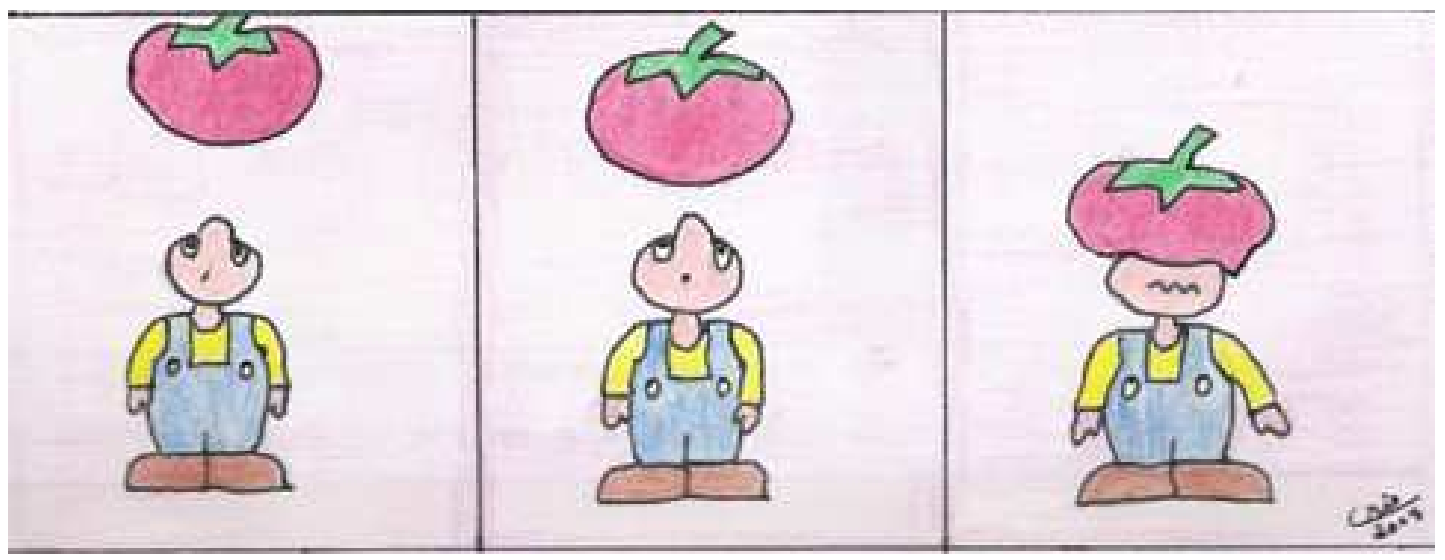

Figura 1

Um dos efeitos possíveis ao se efetuar a transição entre as cenas é o que se pode verificar na ilustração anterior. Nela, a mudança ocorrida entre cada quadro é pequena, exigindo pouca 'conclusão' por parte do leitor. Estamos diante de uma representação de movimento que se assemelha à câmera lenta utilizada no cinema.

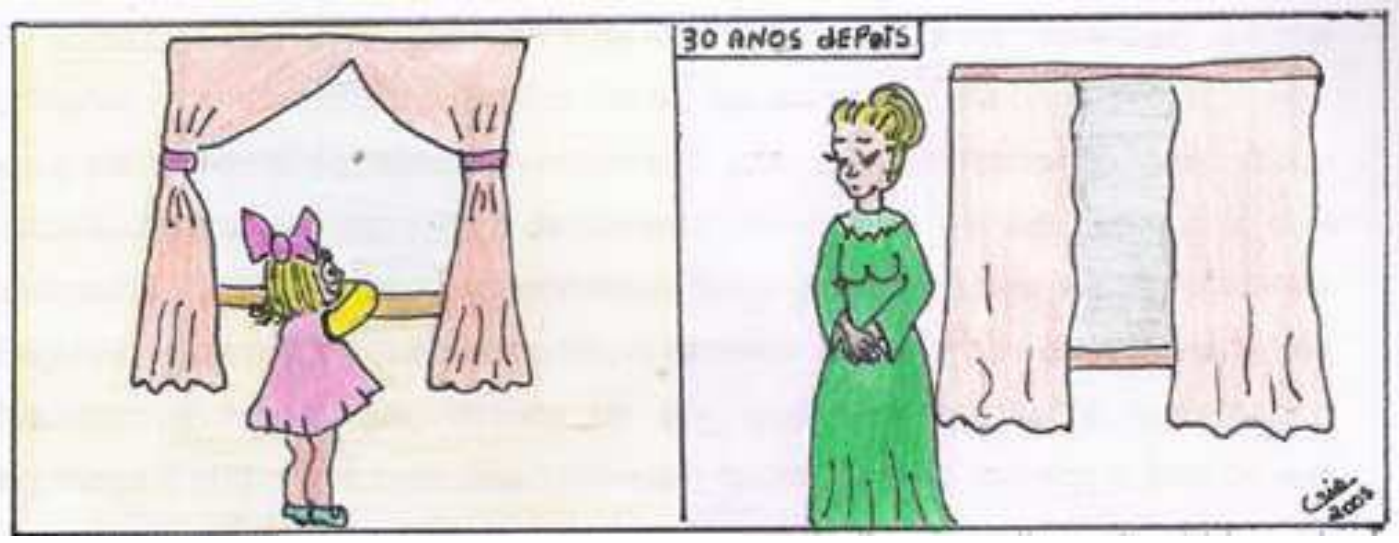

Figura 2

Nesta outra ilustração, a alteração entre os quadros nos leva a uma mudança significativa no tempo (a informação na legenda do $2^{\circ}$ quadro nos indica que se passaram 30 anos). Neste caso, a participação do leitor deve ser maior, já que este necessitará dar um grande salto temporal entre cada imagem apresentada.

Outro recurso utilizado na elaboração dos quadrinhos e que contribui para sua eficiência comunicativa é a forma dos quadros. Segundo McCloud (2002), o quadro (vinheta) é o ícone mais importante dos quadrinhos, revelando-se como um indicador da 
divisão do tempo e do espaço nesta produção artística. Ao mover os olhos pelo espaço da página, o leitor também tem a sensação de se mover no tempo. Devido a sua importância, a forma dos quadros ou até a ausência destes influenciará a experiência da leitura. Assim, um quadro sem contorno pode dar mais leveza ou agilidade à leitura, enquanto uma imagem que extrapola os espaços pode intensificar a dramaticidade de uma cena, isto só para citar algumas das muitas possibilidades interpretativas.

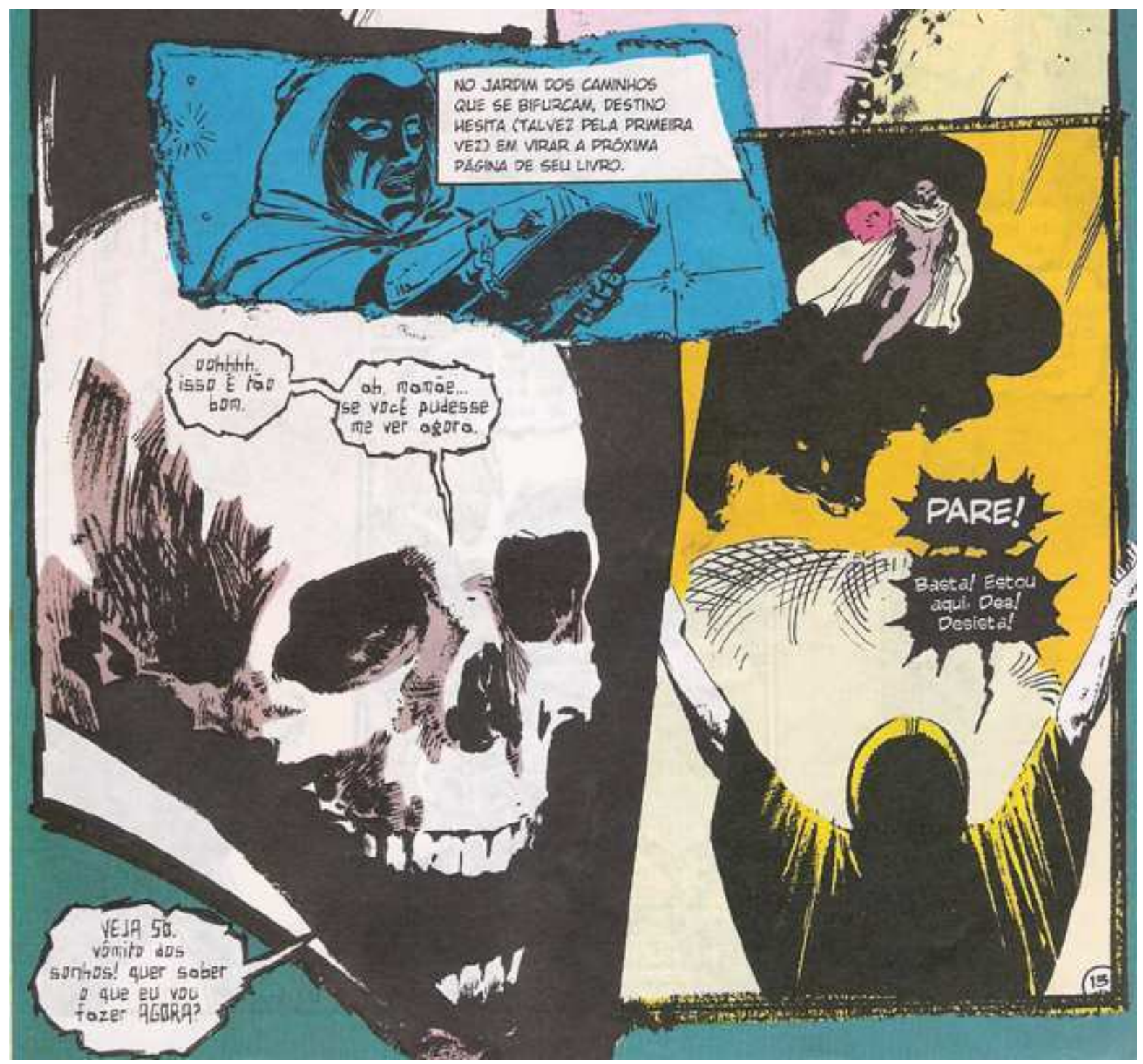

Figura 3

Nos trechos da HQ Sandman, Prelúdios e Noturnos, em que vemos o confronto entre duas personagens (John Dee, um indivíduo perturbado representado pela enorme 
figura em forma de caveira, e o senhor dos Sonhos, que surge ao final da página, de costas), os quadros com formato irregular e sem contorno, juntamente com a sobreposição de imagens, os tons escuros e os tipos de balões e letras utilizadas (que se modificam a cada personagem), acentuam o caráter dramático e intenso das cenas.

\section{Enquadramento e ponto de vista}

Quando observamos as histórias colocamo-nos do outro lado de uma "câmera" e são as diferentes focalizações desta que nos conduzem pela seqüência apresentada. A utilização de planos fixos, panorâmicas, close-up, travelling e outros recursos fílmicos são constantes nos quadrinhos e ajudam a construir uma comunicação ágil e eficiente com o leitor, participante ativo neste processo.

A utilização de planos é um exemplo disso. Nos quadrinhos, as possibilidades criativas a partir da composição através de planos cinematográficos são muito amplas. $\mathrm{Na}$ composição da obra quadrinística é possível identificar, assim como ocorre no cinema, cerca de sete planos: panorâmico, em que se tem uma visão geral e distanciada da paisagem; conjunto, que apresenta as personagens dos pés à cabeça; americano, revelando as personagens até a altura das coxas/joelhos; médio, cujas personagens surgem até a cintura; primeiro plano (close up), que permite ver a personagem ao nível dos ombros, possibilitando uma melhor visualização do seu rosto, e o plano em grande detalhe (extreme close up), que mostra um pormenor da imagem, revelando assim uma maior força expressiva.

Os diferentes pontos de vista nos quadrinhos se dão pelas diversas posições em que a ilustração é revelada (do ponto de vista de quem vê e de como vê estas imagens). Remetendo mais uma vez aos recursos cinematográficos, poderemos ter o ponto de vista normal - o mais objetivo, correspondendo ao campo de visão que se revela quando olhamos para frente; o plongée - visão de cima para baixo, mostrando uma imagem esmagada ou encurralada e sendo utilizada, muitas vezes, para ressaltar uma situação de perigo; o contre-plongé - focaliza a personagem/situação de baixo para cima e é utilizada para exaltar, engrandecer, mostrar a personagem mais forte do que é etc. 

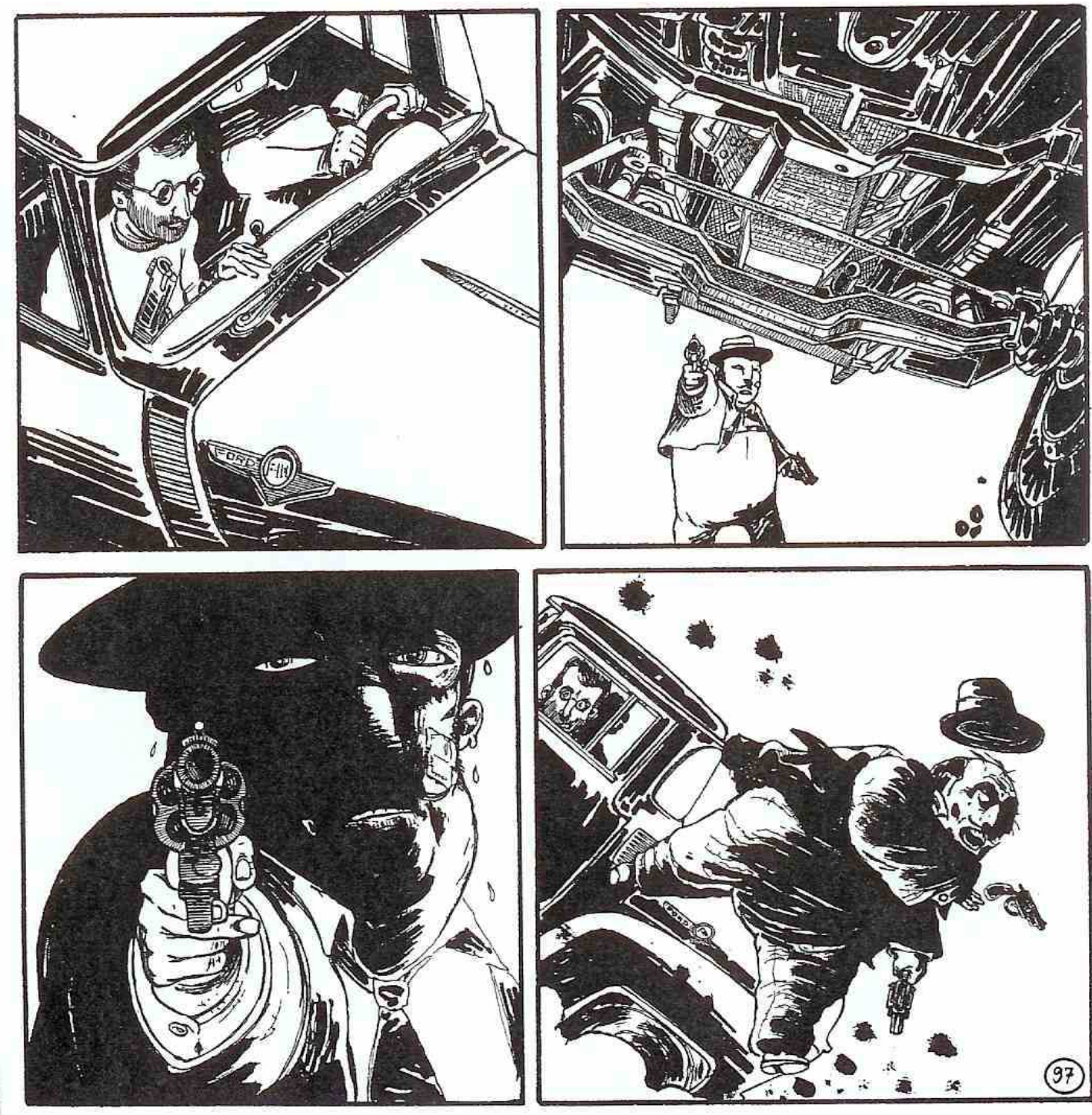

Figura 4

Nas imagens retiradas da HQ de Lourenço Mutarelli, O Dobro de 5, temos um bom exemplo de composição através de planos cinematográficos. Estamos diante de uma seqüência de ação, em que alguns homens em um carro perseguem o detetive Diomedes, protagonista da estória. A sucessão de tomadas revela o movimento e a dramaticidade presente nas cenas: inicialmente temos um carro, focalizado de cima (plongée); na seqüência nos deparamos com uma tomada ousada, na qual podemos visualizar as engrenagens do veículo, ao mesmo tempo em que vemos ao fundo a figura de um homem (o detetive Diomedes), mostrado através de um plano americano (até a altura das coxas); no quadro seguinte nos deparamos com um close up do detetive com a arma na mão, como 
se a "câmera" tivesse se aproximado do seu rosto (apesar do jogo de luz e sombras, que deixa a personagem pouco visível). Neste momento, podemos ver algumas gotas caindo do rosto de Diomedes, o que pode apontar para o fato de que ele sente medo. Na última vinheta, a imagem do detetive de lado, bem como sua expressão assustada, nos indica que este fora atropelado pelo carro.

\section{Balões e legendas - recursos para a voz over e off nos quadrinhos}

A narração nos quadrinhos se faz através das imagens (pictóricas e verbais), do uso dos balões (com ou sem texto) e das legendas (caixas de informação que acompanham as imagens). O balão, onde é inserido a fala ou o pensamento das personagens, é importante elemento das HQs. Conforme explica Cagnin, “o balão, criação original dos quadrinhos (...) é o elemento que indica o diálogo entre as personagens e introduz o discurso direto na seqüência narrativa" (CAGNIN, 1975, p.121). O apêndice (ou rabicho) em forma de flecha que sai do balão e que está voltado para a personagem marca a relação do texto com a imagem referente, indicando quem está falando. Outro aspecto importante do balão é que este também assume um papel imagético, já que seu formato pode indicar sentimentos, atitudes e as mais variadas emoções e intenções.

A legenda (caixa de informações) aparece ao lado do balão como outro importante elemento narrativo. Normalmente ocupa a parte de cima do quadro (vinheta) que contém a imagem, porque é convencionalmente onde se inicia a leitura. É neste espaço que, quando se faz necessário, o narrador toma a palavra e conta suas aventuras em retrospecto, numa narração que não se oriunda das imagens mostradas na respectiva vinheta que a acompanha.

Estes dois elementos, por sua vez, auxiliam na construção de um efeito bastante utilizado no cinema: a presença da voz narrativa cuja fonte não se faz visível em cena. A voz extradiegética, que não é audível por quem está na cena, pois sua fonte não participa da mesma (voz over), pode ser identificada nos quadrinhos através do uso da legenda. Um caso típico da utilização deste recurso é, no cinema, os filmes noir, que trazem a figura de um narrador-detetive contando suas aventuras em retrospecto. Aliás, vale destacar que a combinação da voz over (fora da diegese) e o flashback são dois dispositivos que o noir desenvolveu, trazendo o toque individual de um herói solitário em oposição a um mundo perigoso e hostil (XAVIER, Editora Brasiliense, 1993). Nos quadrinhos, um exemplo da 
utilização da voz over está na satirização deste gênero feita por Luís Fernando Verissimo e Miguel Paiva na HQ Ed Mort.

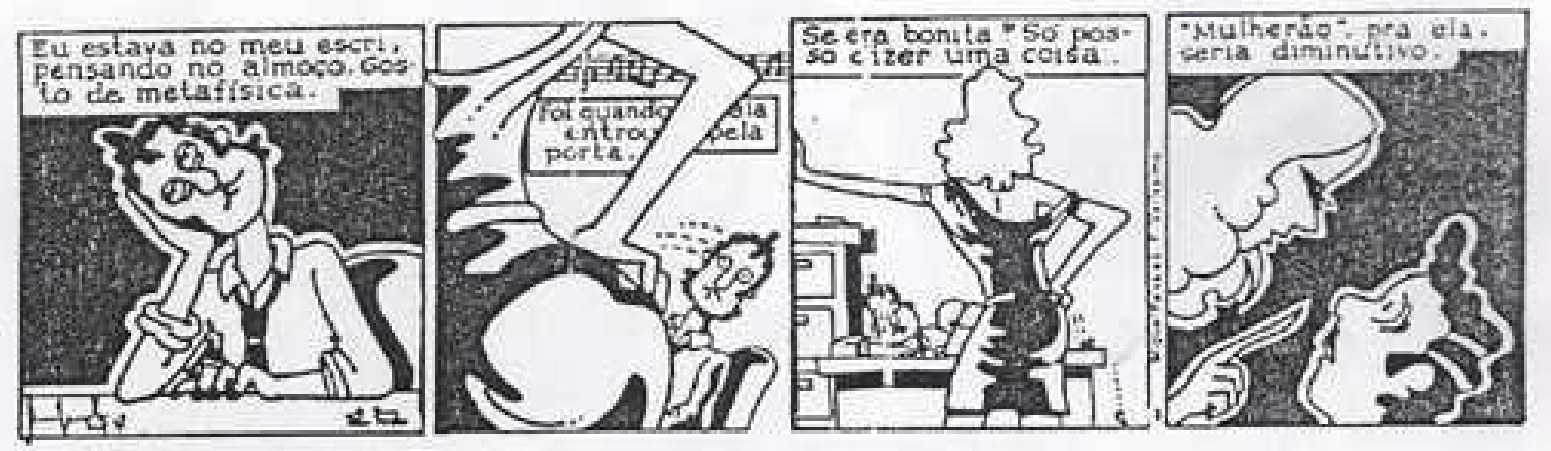

Figura 5

Na ilustração anterior, extraída da HQ Ed Mort Procurando o Silva, a voz over é representada pela presença da legenda narrando em flashback os fatos que motivam a ação do herói: uma mulher, chamada sra. Silva, procura o detetive Ed Mort para que este encontre seu marido desaparecido. O humor predomina nas falas de Ed, como no momento em que ele relaciona seu almoço com a metafísica, sugerindo a quase impossibilidade de conseguir realizá-lo. A presença da sra. Silva (e sua caracterização) remete à figura da mulher envolvente dos filmes noir: formas sinuosas e postura sedutora (o que desencadeia o encantamento imediato de Ed por ela).

Outra forma de utilização da voz no cinema e que também se faz presente nos quadrinhos é a da voz off, aquela em que a fonte, o sujeito falante, não está visível na imagem focalizada, mas participa da cena e é ouvido por quem atua naquele momento. Nas HQs, a voz off se faz presente por meio do uso dos balões sem a representação da personagem que fala em cena (neste caso o apêndice do balão se dirige a um personagem que está fora do quadro mostrado). No quadrinho de Ed Mort, um exemplo da voz off pode ser observado no trecho em que ele é ameaçado por Manecão, um dos comparsas do vilão chamado Nogueira que não quer que Silva seja encontrado por Ed. 


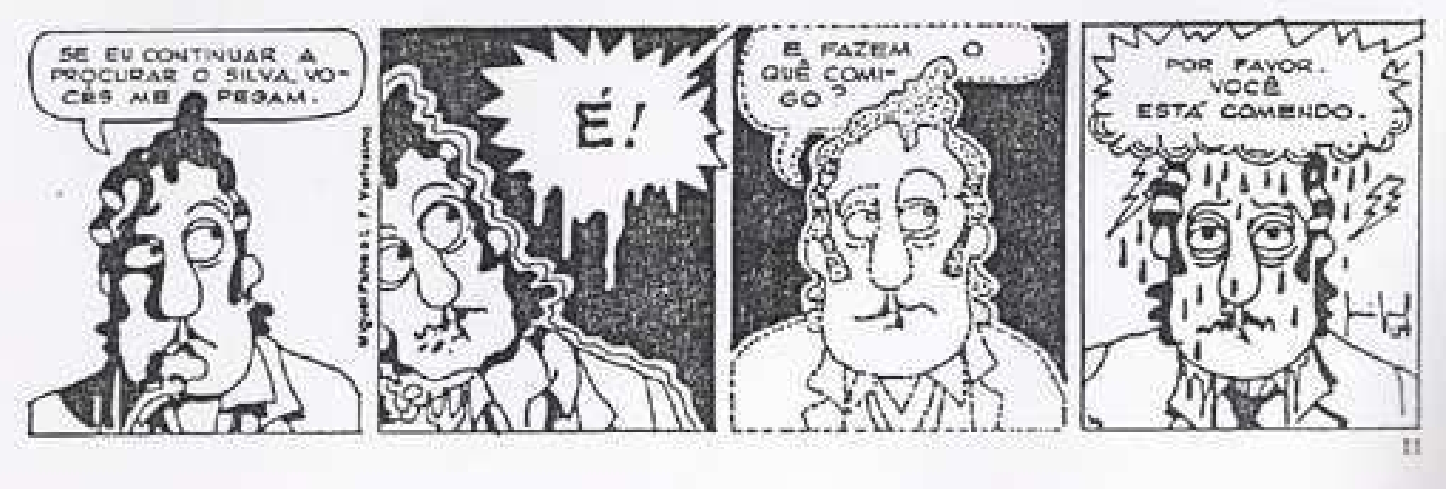

Figura 6

Nesta seqüência temos na ilustração apenas o rosto em close up de Ed sem a presença de outra personagem em cena. A fala de Ed é indicada por balões com apêndices voltados para ele, enquanto a fala do Manecão surge na cena com o apêndice voltado para fora do quadro. Os balões se mostram extremamente visuais neste momento: o que contém a fala do Manecão apresenta-se num formato recortado e irregular (representando um grito, uma fala rígida, gelada, nervosa), o uso da letra em caixa alta, na segunda vinheta, reforça este efeito. Já a fala de Ed, bem como sua imagem no terceiro quadro, surgem tracejadas e claras, denotando medo diante da ameaça. Este efeito é ampliado no quarto quadro com a imagem do rosto de Ed rodeado por gotinhas e raios.

\section{Expressividade em ação}

A onomatopéia é outro importante recurso usado nos quadrinhos. Por meio dela procura-se transmitir, sobretudo, a idéia de ruído. Seu uso, além da significação lingüística e sonora dos grafemas, traz uma característica extremamente visual bastante explorada pelos desenhistas. Vale ressaltar que algumas delas, devido à influência dos quadrinhos americanos no mundo, originam-se de vocábulos oriundos daquele país, como por exemplo: crash (colidir, bater), splash (chapinhar, esguichar), sniff (cheirar).

As linhas e a utilização do fundo borrado (com destaque para a imagem em primeiro plano) são empregadas para intensificar a idéia de movimento, ampliando a expressividade das narrativas em quadrinhos. 
Ziraldo, na HQ Pererê, faz uso de uma profusão de onomatopéias e linhas para representar e intensificar o movimento de perseguição sofrido pela onça Galileu. O uso da expressão 'Bângui' no primeiro quadro nos remete à idéia de tiros. No quadro seguinte temos a imagem de Galileu caído no chão - as linhas de movimento juntamente com a onomatopéia 'plaft' reforçam a idéia de queda.

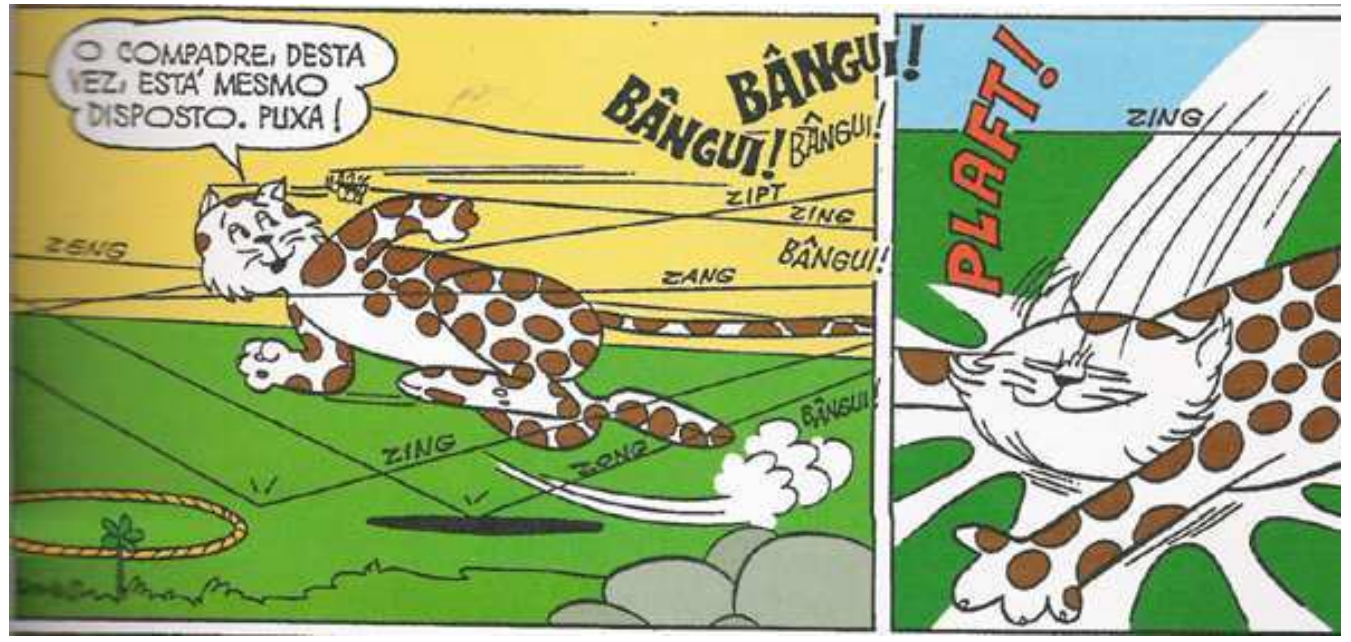

Figura 7

O tipo de traço (se natural ou expressionista), a utilização ou não de cores, a presença do claro/escuro e muitos outros elementos contribuem para a construção narrativa nos quadrinhos, que se apresenta, muitas vezes, embalada pelo ritmo cinematográfico. É preciso, pois, que conheçamos melhor suas possibilidades criativas e as usemos para realizar aquela que se tornou, desde os tempos das cavernas, uma das maiores necessidades humanas: a comunicação.

\section{Referências bibliográficas}

BARBIERI, Daniele. Los lenguajes del cómic. Barcelona: Paidós, 2002. BETTON, Gérard. Estética do cinema. São Paulo: Martins Fontes, 1987. CAGNIN, Antônio Luiz. Os quadrinhos. São Paulo: Ática, 1975.

CIRCE, Moacy. A linguagem dos quadrinhos. Petrópolis: Vozes, 1971. Para ler os quadrinhos. Petrópolis: Vozes, 1972.

COELHO, Nelly Novaes. Literatura Infantil: Teoria, Análise, Didática. São Paulo: Ática ECO, Umberto. Apocalípticos e integrados. São Paulo: Perspectiva, 2004. EISENSTEIN, Sergei. A forma do filme. Rio de Janeiro: Jorge Zahar, 2002. O sentido do filme. Rio de Janeiro: Jorge Zahar, 2002.

EISNER, Will. Narrativas Gráficas. São Paulo: Devir, 2005. 
LEONE, Eduardo; MOURÃO, Dora Maria. Cinema e montagem. São Paulo: Ática, 1993, p.13

McCLOUD, Scott. Desvendando Quadrinhos. São Paulo: M. Books, 2. ed., 2002.

MOYA, Álvaro de. História da História em Quadrinhos. São Paulo: Brasiliense, 1994.

SANTAELLA, Lucia. Imagem e cognição, semiótica, mídia. São Paulo: Iluminuras, 1998. Palavra, imagem \& enigmas. São Paulo: Revista USP, n. 16.

XAVIER, Ismail. Alegorias do Subdesenvolvimento: Cinema Novo, Tropicalismo e Cinema Marginal. São Paulo: Brasiliense, 1993.

\section{Figuras}

Figura 1: OLIVEIRA, Maria Cristina X. de. COPYRIGHT

Figura 2: OLIVEIRA, Maria Cristina X. de. COPYRIGHT

Figura 3: GAIMAN, Neil; DRINGENBERG, Mike; JONES III, Malcolm. Sandman, Prelúdios e Noturnos. São Paulo: Brainstore, 2000, p.7.

Figura 4: MUTARELLI, Lourenço. O Dobro de 5. São Paulo: Devir, 1999, p.37.

Figura 5: VERISSIMO, Luis Fernando; PAIVA, Miguel. Ed Mort em: procurando o Silva. Porto Alegre: L\&PM, 1991, p.4.

Figura 6: VERISSIMO, Luis Fernando; PAIVA, Miguel. Ed Mort em: procurando o Silva. Porto Alegre: PM, 1991, p.11.

Figura 7: PINTO, Ziraldo Alves. Todo Pererê. São Paulo: Moderna, 2002, p.19. 